\title{
SOLIDARIDAD COMUNICATIVA Y \\ RECONOCIMIENTO: CONTRIBUCIONES DE LA \\ FILOSOFÍA PARA LA PAZ AL PROYECTO UNESCO DE UN NUEVO HUMANISMO

\section{Communicative Solidarity and Recognition: Contributions of Philosophy for Peace to the Unesco Project of New Humanism}

Solidariedade comunicativa e reconhecimento: contribuições da filosofia para a paz ao projeto Unesco de um novo humanismo

\section{RECIBIDO:11DE NOVIEMBREDE 2015}

es

\section{RESUMEN}

El objetivo de este artículo es explicar la contribución qué hace la Cátedra Unesco de Filosofía para la Paz al proyecto Unesco de un nuevo humanismo. El artículo presenta dos categorías centrales en torno a las cuales la filosofía para la paz contribuye al desarrollo de la renovación del humanismo, a saber: la solidaridad comunicativa y el reconocimiento. En este dominio de investigación, se exponen los principios éticos que ponen en juego estas dos categorías analíticas.

\section{EVALUADO:11DEDICIEMBREDE 2015}

Ismael Cortés Gómez (España)

Universitat Jaume I, Castellón /

Instituto Interuniversitario de

Desarrollo Social y Paz.

ismaelcortes@hotmail.com

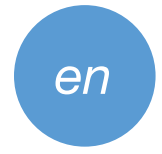

\section{ABSTRACT}

The intention of this article is to explain the contribution of the Unesco Cátedra of Philosophy for Peace to the Unesco project of a new humanism. The paper presents two central categories around which philosophy for peace contributes to the development of the renewal of humanism, namely: communicative solidarity and recognition. In this research domain, the ethical principles that put these two analytical categories into play are exposed..
ACEPTADO:1DEFEBRERODE 2016

\section{RESUMO}

O objetivo deste artigo é explicar a contribuição que faz a Cátedra Unesco de Filosofia para a Paz ao projeto Unesco de um novo humanismo. $\mathrm{O}$ artigo apresenta duas categorias centrais em torno às quais a filosofia para a paz contribui ao desenvolvimento da renovação do humanismo, a saber: a solidariedade comunicativa e o reconhecimento. Em este domínio de pesquisa, expõem-se os princípios éticos que põem em jogo estas duas categorias analíticas..
PALABRAS CLAVE: solidaridad comunicativa, reconocimiento, filosofía para la paz, nuevo humanismo, transformación social no violenta.
KEYWORDS: communicative solidarity, recognition, philosophy for peace, new humanism, non-violent social transformation..
PALAVRAS CHAVE: solidariedade comunicativa, reconhecimento, filosofia para a paz, novo humanismo, transformação social não violenta.. 


\section{INTRODUCCIÓN}

En el editorial de El Correo de la Unesco de diciembre de 2011, dedicado al proyecto Unesco de un nuevo humanismo, Irina Bokova ${ }^{1}$ afirmaba: "Los valores humanistas son el fundamento filosófico de la Unesco... el humanismo es una idea que debemos reinventar" (2011, p. 5). En este mismo editorial, Bokova definía el proyecto Unesco de un nuevo humanismo a partir de dos postulados: 1) una concepción del progreso como un proceso de crecimiento del saber que las sociedades tienen sobre sí mismas y sobre sus posibilidades de desarrollar modelos pacíficos de convivencia y 2) una definición de la "justicia" a partir del equilibrio dinámico entre la pluralidad ideológica y la normativa contingente que producen las sociedades liberales democráticas y dan cuenta así del carácter abierto, progresivo e inacabado de la justicia.

En el presente artículo, mi intención es explicar la contribución que hace la Cátedra Unesco de Filosofía para la Paz al proyecto Unesco de un nuevo humanismo. Para ello, voy a presentar dos categorías analíticas, la solidaridad comunicativa y el reconocimiento, poniendo de relieve su potencial para orientar procesos democráticos de transformación social no violenta. ${ }^{2}$ Estas dos categorías serán explicadas desde el marco epistemológico desarrollado por la Cátedra Unesco de Filosofía para la Paz, que se sitúa en la tradición de la teoría

Panorama noviembre de 2009.

2 Tomamos el concepto de no violencia en su sentido sociopolítico, así pues, nos distanciamos de la aplicación de este concepto a otros niveles más amplios, tal y como sería el sentido religioso que aquel adquiere en la religión budista. En concreto, aquí hablamos de la no violencia como una estrategia política que persigue generar una transformación social, moral y cultural como normativa, sin emplear la violencia en ningún momento. Para profundizar en los usos del concepto sociopolítico de no violencia dentro de la Cátedra Unesco de crítico-comunicativa. ${ }^{3}$ Dentro de este marco epistemológico, y en torno al objetivo general que plantea la propuesta Unesco de un nuevo humanismo: "combinar el compromiso científico con la verdad y el compromiso ético con la justicia” (Bokova, 2010, p. 3), este artículo se propone trabajar sobre tres líneas específicas:1) redefinir la relación entre desarrollo moral, cultura deliberativa y democracia, 2) demarcar un horizonte ético-normativo capaz de integrar la pluralidad de ideologías que configuran el paisaje político de las democracias liberales y 3) proponer un modelo de intervención social científica que contribuya a dinamizar procesos democráticos de transformación social no violenta.

Para organizar estas líneas de trabajo, el artículo se estructura en tres apartados: 1) el primer apartado expone los fundamentos epistemológicos de la filosofía para la paz, a partir del diálogo con la ética de Lévinas, que revela el vínculo entre las nociones de solidaridad comunicativa, violencia y responsabilidad moral; 2) el segundo apartado profundiza en el diálogo que establece la filosofía para la paz con la teoría social del reconocimiento de Honneth y examina el vínculo entre las ideas de indignación, conflicto y reconocimiento, y 3) el último apartado recupera los argumentos presentados en los dos apartados anteriores para situarlos respecto del potencial práctico del proyecto de un nuevo humanismo en relación con la ética del trabajo del científico social.

\section{SOLIDARIDAD COMUNICATIVA, VIOLENCIA Y RESPONSABILIDAD MORAL}

En diálogo con la ética de Lévinas (Lévinas, 2003), la filosofía para la paz ha producido la categoría de

3 Las investigaciones de Vicent Martínez, director honorífico y fundador de 1 a Cátedra Unesco de Filosofía para la Paz, en torno al giro lingüistico y el giro pragmático de la filosofía han sentado los fundamentos epistemológicos de la filosofía para la paz. El giro lingüistico inaugura una ontología según la cual el lenguaje codifica tanto el pensamiento como la voluntad humana, es decir que el lenguaje codifica pensamiento y acción. La aplicación del giro lingüistico y pragmático a la filosofía ética y política permitió la emergencia de la epistemología comunicativo-crítica (Apel, 1991; Habermas, 2010; Martínez, 1999). En este marco, se concibe el diálogo como el mecanismo básico de coordinación del pensamiento y la acción social. Basándose en este principio axiomático, la epistemología comunicativo-crítica defiende que el libre ejercicio del diálogo produce su propia normativa, abierta y dinámica, la cual tiene como límites las propias condiciones de posibilidad del diálogo: veracidad, contrastabilidad, falibilidad y pretensión de consenso. El potencial crítico de esta epistemología radica en su capacidad de señalar las barreras que bloquean el diálogo entre la esfera institucional y las demandas de justicia que se generan en el seno de la sociedad civil. Asimismo, otra dimensión crítica de la epistemología comunicativa radica en su capacidad de identificar posiciones fundamentalistas respecto de concepciones últimas y absolutas de la justicia, las cuales operan en contra del principio liberal y democrático de tolerancia hacia el pluralismo ideológico. Para profundizar en los fundamentos de la epistemología comunicativo-crítica dentro de la Cátedra Unesco de Filosofía para la Paz, recomiendo los trabajos de Martínez (2010) y Forastelli (2013). 
solidaridad comunicativa con la cual resalta la dimensión pragmática de la comunicación, esto es, sus consecuencias para la vida ética y política. Desde este enfoque lingüístico-pragmático, la idea de solidaridad comunicativa funciona como una categoría prescriptiva que remite a una metodología dialógica inclusiva orientadora de procesos democráticos de toma de decisiones colectivas (Martínez, 2001). En esta línea de interpretación, Vicent Martínez ${ }^{4}$ (2001, p. 45) define la solidaridad comunicativa utilizando un argumento contrafáctico, y sostiene que la solidaridad comunicativa se rompe en el momento en que, social o institucionalmente, bloqueamos la posibilidad de que un determinado sujeto (individual o colectivo) exprese su opinión sobre una decisión que afecta a alguna de las dimensiones que constituyen su dignidad: dignidad corporal, dignidad jurídica o dignidad cultural. En coherencia con esta definición, este autor identifica la ruptura de la solidaridad comunicativa como el nivel fundamental donde se origina el menosprecio moral a la dignidad humana y, por ende, el origen de la violencia:

\section{La solidaridad se muestra como originaria en las relaciones humanas cuando hay comunicación. La violencia comienza con la ruptura de esa solidaridad comunicativa, es decir, la violencia comienza con la falta de reconocimiento de unos/as a otros/as como seres competentes para comunicarnos y expresar nuestra opinión sobre los temas que nos afectan [cursiva en el original] (Martínez, 2005, pp. 72-73).}

En colaboración con Irene Comins Mingol y Sonia París Albert, investigadoras de la Cátedra Unesco de Filosofía para la Paz, Martínez ha profundizado en la idea de la formación dialógica e intersubjetiva de la responsabilidad moral:

En nuestra investigación afrontamos un nivel fundacional que precede a la individuación autorreflexiva del ego en su forma concreta. Es una fundamentación que conecta el ego con los otros egos anterior a la individuación auto-reflexiva de cualquier ego. El tema de la intersubjetividad da un giro desde una posición YO/OTRO a una cuestión de co-

4 Vicent Martínez es director honorífico y fundador de la Cátedra Unesco de Filosofía para la Paz constitución de mónadas ${ }^{5}$ (París, Comins y

Martínez, 2011, p. 343).

Esta investigación sobre la formación dialógica e intersubjetiva de la responsabilidad moral resulta de una lectura actualizada de la ética de Lévinas. Según el propio Lévinas, la formación de la conciencia moral se desarrolla con la praxis de la escucha activa de las demandas del otro (Lévinas, 2003, p. 58). Así, de acuerdo con Lévinas, el genuino aprendizaje moral "es el resultado de un gesto de aproximación al otro que demanda justicia” (2006, p. 20). En esta línea de investigación ética, el diálogo entre la filosofía para la paz y la ética de Lévinas se articula en torno a una tesis fundamental que Martínez formula así: "La responsabilidad moral se desarrolla en el mutuo ejercicio de darnos y pedirnos razones por lo que nos hacemos los unos a los otros" (Martínez, 2010, p. 14).

En la conferencia titulada "Reflexiones para nuevos humanismos”, Martínez (2011) tomó como referencia la ética dialógica de Lévinas, e hizo hincapié en que la renovación del humanismo obedece a una doble toma de conciencia: por un lado, al reconocimiento del factum del sufrimiento humano en las formas actuales de desigualdad, discriminación o violencia; y por otro, al reconocimiento del desafío ético que suponen estas experiencias de sufrimiento para quienes se dedican a la política y a las ciencias sociales.

Esta reflexión que delineaba Martínez sobre el nuevo humanismo remite a un complejo campo de relaciones dialógicas, ${ }^{6}$ en el cual los discursos que producen los colectivos sociales que sufren situaciones de injusticia interpelan a los discursos científicos y políticos que pretenden ofrecer soluciones a tales situaciones. De acuerdo con el planteamiento ético-dialógico de Lévinas, podría argumentarse que este ejercicio dialógico constituye el mecanismo que conduce a la democracia hacia la excelencia, "cuyo liberalismo básico corresponde al cuestionamiento ético, profundo e incesante de la justicia” (Lévinas, 1993, p. 39).

\footnotetext{
5 En el sistema filosófico leibniziano, que junto con el cartesianismo constituye los orígenes del racionalismo y del subjetivismo moderno, una mónada es una unidad simple y autónoma de entendimiento que, desde su perspectiva, representa la totalidad de las relaciones que componen el mundo (Audi, 2004, p. 591).

6 En el marco epistemológico comunicativo-crítico en el que se sitúa la filosofía para la paz, la democracia adquiere su legitimidad en función de los cauces de comunicación que la esfera institucional abre hacia los discursos que produce la sociedad civil (Comins y París, 2012; Martínez, 2009).
}

Solidaridad comunicativa y reconocimiento: contribuciones de la filosofía para la paz al proyecto Unesco de un nuevo humanismo 


\section{INDIGNACIÓN, CONFLICTO Y RECONOCIMIENTO}

Situándose en la tradición teórica de la epistemología comunicativo-crítica, la Cátedra Unesco de Filosofía para la Paz desarrolla un marco analítico que investiga la legitimidad de los marcos institucionales de justicia respecto del consenso/disenso social que se configura en la esfera de la sociedad civil, es decir, en el espacio social, participativo y deliberativo en el que se forma la opinión pública (Habermas, 2006; Martínez, 2008).

Desde el enfoque comunicativo-crítico, la filosofía para la paz apuesta por un modelo de praxis política que remite a un ideal de democracia liberal articulada socialmente por una cultura deliberativa. En este marco, adquiere especial relevancia el estudio de las luchas sociales y las iniciativas de activismo cívico, que cuestionan los marcos normativos y culturales que normalizan situaciones de injusticia. Dentro de este campo teórico se forma un área de intersección entre la filosofía para la paz y la teoría social del reconocimiento respecto de la investigación de las demandas de justicia que emergen de situaciones de desigualdad, discriminación o violencia (Honneth, 2012; París, 2015). En esta área de intersección teórica, la conceptualización positiva del conflicto constituye uno de los nodos de convergencia más relevantes entre la filosofía para la paz y la teoría social del reconocimiento:

1. La filosofía para la paz comprende el conflicto como parte inherente de los procesos democráticos de transformación social no violenta, siempre y cuando el conflicto sea dirimido mediante procedimientos políticos basados en la negociación, el diálogo y la persuasión (París, 2009, p. 23).

2. La teoría social del reconocimiento entiende el conflicto como la condición para la evolución progresiva de los marcos normativos y culturales que regulan las relaciones sociales. En esta línea de interpretación, Honneth (1996) defiende que históricamente las luchas de los grupos oprimidos han contribuido a la institucionalización de principios de justicia que hoy constituyen la base de las constituciones democráticas liberales. En coherencia con esta interpretación del conflicto, Honneth argumenta: "Las luchas por el reconocimiento de los grupos históricamente excluidos del sistema universal de derechos, más allá de defender un interés particular de emancipación, han contribuido al perfeccionamiento de una idea universal de la justicia (1996, p. 5).

A esta conceptualización del conflicto subyace una tensión dialéctica que tiene que ver con el modo en que las luchas sociales han contribuido históricamente a expandir los límites de la universalidad de la justicia. Esta tensión encierra una doble potencialidad:

Por un lado, esta tensión dialéctica permite denunciar la imperfección de las formas históricas y contingentes de justicia; al mismo tiempo, esta tensión abre un proceso de revisión y transformación de los marcos fácticos de justicia hacia un horizonte utópico de justicia, corrigiendo gradual y progresivamente situaciones de desigualdad, discriminación y violencia.

Por otro lado, esta tensión dialéctica encierra el riesgo de que la pluralidad de ideologías que cuestionan los límites de la universalidad de la justicia (siempre imperfecta, contingente e inacabada) provoquen una fragmentación de la conciencia social sobre la noción de justicia y segmente así el entendimiento colectivo sobre los principios básicos de consenso sobre los que cualquier sociedad aspira a alcanzar un acuerdo. Este riesgo podría traducirse en un escenario de choque violento entre ideologías incapaces de encontrar puntos de convergencia sobre los que iniciar un proceso de diálogo.

Otro de los nodos que vinculan el análisis de la filosofía para la paz y la teoría social del reconocimiento lo podemos situar en el dominio de la investigación sobre las motivaciones morales implicadas en las luchas sociales. En este orden de investigación, Honneth localiza un nivel fundacional que remite las luchas sociales a experiencias colectivas de daño a la dignidad; experiencias que él mismo conceptualiza a partir del binomio reconocimiento/menosprecio. En palabras del propio Honneth: "Los motivos de rebelión y de resistencia social se constituyen en un espacio de experiencias morales de menosprecio que brotan de la lesión de expectativas profundas de reconocimiento" (1996, p. 264).

En este nivel de análisis sobre las motivaciones morales implicadas en las luchas sociales, considero de especial relevancia las investigaciones éticas de París (2013, 2015), que relacionan sistémicamente las nociones de indignación, conflicto y reconocimiento. En diálogo con la teoría social del reconocimiento de Honneth, París diseña una tipología tripartita de los distintos modos de indignación que subyacen a la organización de las luchas sociales. París (2015, p. 63) distingue tres experiencias de indignación: 1) la indignación provocada por un daño que menosprecia nuestra dignidad corporal (o la de los otros), 2) la indignación provocada por 
un daño que menosprecia nuestra dignidad jurídica (o la de los otros) y 3) la indignación provocada por un daño que menosprecia nuestra dignidad cultural (o la de los otros).

Más allá de los nodos de convergencia que vinculan las investigaciones de París (2015, pp. 64-65) y Honneth (2011, pp. 40-43), creo que la propuesta de París añade un elemento diferencial respecto de la teoría de Honneth.

Por su lado, Honneth conceptualiza el sujeto político "como sujeto involucrado existencialmente, que toma conocimiento de los estados de sensibilidad no de manera neutral, sino afectado por ellos en relación consigo mismo" (2007, pp. 76-77).

Mientras que, por otro lado, a través de una lectura actualizada de la fenomenología de los sentimientos morales de Strawson (1974), París (2013) propone que el compromiso con la transformación de las situaciones de injusticia no parte exclusivamente de un sentimiento de indignación provocado por una experiencia de menosprecio moral sufrida en primera persona, sino que la solidaridad también desempeña un papel muy importante a la hora de comprometernos con la transformación de situaciones de injusticia.

\section{FILOSOFÍA PARA LA PAZ, NUEVO HUMANISMO Y TRANSFORMACIÓN SOCIAL NO VIOLENTA}

En este último apartado, recuperaré las reflexiones expuestas sobre la solidaridad comunicativa y el reconocimiento, para situarlas respecto $\mathrm{DE}$ mi propia visión sobre el modo en que la renovación del humanismo desafía una serie de dilemas epistemológicos y prácticos, relativos al compromiso ético del trabajo científico.

Recuperando el objetivo general del proyecto Unesco de un nuevo humanismo, "combinar el compromiso científico con la verdad y el compromiso ético con la justicia” (Bokova, 2010, P. 3), creo que uno de los principales dilemas a los que se enfrenta este proyecto estaría definido por la disyuntiva entre ciencia y política. Desafiando este dilema, que ha sido formulado en su versión más clásica por la epistemología de Weber (1988) y su propuesta de una ciencia libre de valores, la filosofía para la paz plantea precisamente una defensa del compromiso de las ciencias sociales con la solidaridad como un valor central que ha de guiar el trabajo del científico social (Cortés, 2014).

En esta línea de interpretación, la filosofía para la paz entiende que la solidaridad constituye el principio rector de la ética del trabajo científico, en especial en el campo de las ciencias sociales, y en concreto, de los estudios de paz (Comins, 2008). Este compromiso axiológico se apoya en el siguiente postulado: la finalidad de los estudios de paz no es la neutralidad descriptiva de los fenómenos sociales, sino la gestión no violenta de los conflictos sociales y el diseño de modelos de convivencia basados en el respeto, la tolerancia y el diálogo (Cortés, 2012; Martínez, 1999).

Desde mi punto de vista, otro de los principales dilemas a los que se enfrenta la propuesta de un nuevo humanismo se deriva de su doble compromiso con 1) definir una idea universal de justicia que permita un entendimiento común mínimo sobre la necesidad de proteger la dignidad de todo ser humano y 2) exponer la idea de universalidad de la justicia a la crítica formulada por una pluralidad de ideologías que denuncian la situación de injusticia (desigualdad, discriminación o violencia) que sufren determinados colectivos sociales (Cortés, 2012, p. 81; Martínez, 2001, p. 173). Desafiando este otro dilema, la filosofía para la paz propone que el científico social, sobre todo en el campo de los estudios de paz, debe comprometerse con dinamizar procesos de diálogo y entendimiento entre las distintas ideologías que se disputan la batalla por definir el alcance de la universalidad de la justicia (Cortés, 2014, pp. 204-205). En esta línea de argumentación, la reflexión que hizo Irina Bokova durante la Mesa redonda sobre la actualidad del bumanismo, creo que vino a reforzar esta visión acerca del compromiso científico con la renovación constante de los límites de la universalidad de la justicia: "La justicia no es un a priori que simplemente se aplica como una receta, [la justicia] es el resultado de una investigación, del diálogo” (Bokova, 2010, p. 4).

Retomando el hilo de las reflexiones expuestas sobre los dilemas éticos y epistémicos que desafía el nuevo humanismo, considero que el científico social, en especial en el campo de los estudios de paz, debe desempeñar un rol de facilitador del diálogo entre los distintos relatos que entran en disputa por definir el alcance y los límites de la justicia, en una determinada situación de conflicto
| Solidaridad

comunicativa y

reconocimiento: contribuciones de la filosofía para la paz al proyecto Unesco de un nuevo humanismo 
Ismael Cortés

Gómez I

social. En este sentido, creo que el científico social ha de trascender el espacio puramente universitario y adquirir el compromiso de trabajar con o influir en las distintas esferas donde se construyen y legitiman (o cuestionan) los marcos de pensamiento colectivo en torno a los límites y el alcance de la universalidad de la justicia: 1) los medios de comunicación, 2) los espacios de activismo cívico donde se organizan las luchas sociales y 3) la esfera institucional donde se diseñan los marcos normativos que regulan la convivencia social.

De acuerdo con los principios de solidaridad comunicativa y reconocimiento, considero que la renovación del humanismo se enfrenta al reto de inscribir unos compromisos éticos mínimos que regulen las luchas sociales que cuestionan el alcance y los límites de la universalidad de la justicia y contribuir así a dinamizar procesos no violentos de transformación social basados en el diálogo, la persuasión y la negociación.

\section{CONCLUSIONES}

El propósito de este artículo ha sido explicar cómo las nociones de solidaridad comunicativa y reconocimiento, producidas en el marco epistemológico comunicativo-crítico de la Cátedra Unesco de Filosofía para la Paz, contribuyen al desarrollo de la propuesta Unesco de un nuevo humanismo. Esta exposición me ha habilitado a presentar una determinada concepción sobre el compromiso ético del científico social, en especial en el campo de los estudios de paz.

El artículo ha profundizado en el análisis de los nodos de convergencia que articulan el diálogo de la filosofía para la paz con la ética de Lévinas y con la teoría social del reconocimiento de Honneth. Este análisis me ha permitido poner de relieve: 1 ) una conceptualización de la interrupción de la solidaridad comunicativa como una forma de violencia originaria, la cual estaría basada

Panorama I

pp. 77-831

Volumen 10 I

Número 19 |

Julio-diciembre

2016 I en el menosprecio de la capacidad del sujeto (individual o colectivo) de expresar una opinión razonada sobre una decisión que afecta a su propia existencia y 2) una conceptualización de las luchas sociales respecto de la reacción colectiva ante una determinada situación de injusticia, a la cual subyace un impulso de demanda de reconocimiento de la dignidad moral de los sujetos afectados.
Este análisis ha presentado el conflicto desde su dimensión creativa, es decir, a partir de las posibilidades que abre para iniciar un proceso de transformación social no violenta. En este sentido, el artículo ha conceptualizado el conflicto como la condición para el progreso social, en cuanto posibilita el cuestionamiento tanto de los marcos normativos como de los encuadres morales y culturales que justifican situaciones de injusticia. Esta conceptualización ha ahondado: 1) en la dimensión dialógica del desarrollo de la conciencia moral y 2) en la tensión entre la pretensión de universalidad de la justicia en las democracias liberales y su exposición a la crítica de las distintas ideologías que cuestionan su alcance universal; críticas que emergen de las luchas sociales de colectivos que denuncian situaciones de injusticia manifestadas en las formas de desigualdad, discriminación o violencia.

En este orden expositivo, el artículo finalmente propone que, guiado por los principios éticos que introducen las categorías de solidaridad comunicativa y reconocimiento, el científico social debe comprometerse a trabajar con o influir en distintas esferas que coordinan procesos de pensamiento y acción colectiva: 1) los medios de comunicación, 2) los espacios de activismo cívico y 3) los espacios institucionales encargados de definir los marcos normativos de justicia que regulan la convivencia social.

\section{REFERENCIAS}

1. Apel, K.-O. (1991): Teoría de la verdad y ética del discurso. Barcelona: Paidós.

2. Audi, R. (2004). Diccionario Akal de filosofía. Madrid: Akal.

3. Bokova, I. (1 diciembre 2010). Perspectivas del nuevo humanismo en el siglo XXI. Discurso pronunciado en la Universidad Nacional de San Martín, Buenos Aires.

4. Bokova, I. (2011). Editorial. El Correo de la Unesco, 4, 5 .

5. Comins Mingol, I. (2008). Antropología filosófica para la paz: una revisión crítica de la disciplina. Revista de Paz y Conflictos, 1, 61-88.

6. Comins Mingol, I. y París Albert, S. (2012). Epistemologías para el humanismo desde la filosofía para la paz. Recerca: revista de pensament $i$ anālisi, 12, 5-11. 
7. Cortés Gómez, I. (2012). La filosofía para la paz ante la teoría social del reconocimiento: un diálogo en clave humanista (Tesis de máster, Universitat Jaume I, Castellón, España).

8. Cortés Gómez, I. (2014). 15 años de filosofía para la paz: el lugar de la ética en la investigación para la paz. Revista de Paz y Conflictos, 7, 195-209.

9. Forastelli, F. (2013). Peace profile: Vicent Martínez Guzmán. Peace Review, 25(3), 439-446.

10. Habermas, J. (2006). Political communication in media society: Does democracy still enjoy an epistemic dimension? The impact of normative theory on empirical research. Communication Theory, 16(4), 411-426.

11. Habermas, J. (2010). Teoría de la acción comunicativa. Madrid: Trotta.

12. Honneth, A. (1996). The struggle for recognition: The moral grammar of social conflicts. Cambridge: MIT Press.

13. Honneth, A. (2007). Reificación: un estudio en la teoría del reconocimiento. Buenos Aires: Katz.

14. Honneth, A. (2011). La sociedad del desprecio. Madrid: Trotta.

15. Honneth, A. (2012). Recognition as ideology: The connection between morality and power. En A. Honneth, The I in we: Studies in the theory of recognition (pp. 75-97). Cambridge: Polity Press.

16. Lévinas, E. (1993). El otro, utopía y justicia. Archipiélago: Cuadernos de Crítica De La Cultura, 12,35-41.

17. Lévinas, E. (2003). De otro modo que ser o más allá de la esencia. Salamanca: Sígueme.

18. Lévinas, E. (2006). Ética como filosofía primera. A Parte Rei. Revista de Filosofía, 43, 2-22.

19. López, M. (2001). La no violencia como alternativa política. En F. Muñoz, La paz imperfecta (pp. 181-251). Granada: Editorial de la Universidad de Granada.

20. Martínez Guzmán, V. (1999). Apel en Castellón: del discurso de las humanidades al discurso de la paz. Anthropos, 183, 106-110.

21. Martínez Guzmán, V. (2001). Filosofía para hacer las paces. Barcelona: Icaria.
22. Martínez Guzmán, V. (2005). Podemos hacer las paces: reflexiones éticas tras el 11-S y el 11-M. Bilbao: Desclée de Brouwer.

23. Martínez Guzmán, V. (2008). El papel de la sociedad civil en la construcción de la paz: un estudio introductorio. Barcelona: Icaria.

24. Martínez Guzmán, V. (2009). La nueva agenda de la filosofía para el siglo XXI: los estudios para la paz. Convergencia: Revista de Ciencias Sociales, IA, 91-114. $\mid \begin{aligned} & \text { Solidaridad } \\ & \text { comunicativa y } \\ & \text { reconocimiento }\end{aligned}$

contribuciones

de la filosofía

para la paz al

proyecto Unesco

de un nuevo

humanismo
25. Martínez Guzmán, V. (2010). La filosofía para hacer las paces: fuentes filosófico-biográficas de la investigación para la paz. En I. Comins Mingol y S. París Albert (ed.), Investigación para la paz: estudios filosóficos (pp. 11-24). Barcelona: Icaria.

26. Martínez Guzmán, V. (9 junio 2011).

Reflexiones para nuevos humanismos.

Conferencia en el Centro Unesco ETXEA.

27. París Albert, S., Comins Mingol, I. y Martínez Guzmán, V. (2011). Algunos elementos fenomenológicos para una filosofía para hacer las paces. En Investigaciones Fenomenológicas (pp. 331-348).

28. París Albert, S. (2009). Filosofía de los confictos: una teoría para su transformación pacifica. Barcelona: Icaria.

29. París Albert, S. (2013). Philosophy, recognition, and indignation. Peace Review, 25(3), 336-342.

30. París Albert, S. (2015). Hacia una revalorización de la filosofía en diálogo con la indignación. Convergencia, 22(68), 51-70.

31. Ortega, P. y Pozo, A. (2005). No violencia y transformación social. Barcelona: Icaria.

32. Strawson, P. F. (1974). Freedom and resentment and other essays. Londres: Methuen.

33. Weber, M. (1988). El político y el científico. Madrid: Alianza.
I Panorama

I pp. 77-83

I Volumen 10

I Número 19

I Julio-diciembre I 2016 